\title{
Biology of citrus whitefly, Dialeurodes citri (Ashmead) on Citrus reticulate (Mandarin) var. Kinnow
}

\author{
Tekchand Saini*, Maha Singh Jaglan , S. S. Yadav and Rajbir Garg \\ Department of Entomology, CCS Haryana Agricultural University, Hisar-125004 (Haryana), INDIA \\ *Corresponding author. E-mail: tsaini398@gmail.com
}

Received: November 29, 2015; Revised received: July 20, 2016; Accepted: November 24, 2016

\begin{abstract}
Screen house studies on biology of citrus whitefly, Dialeurodes citri (Ashmead) (Hemiptera: Aleyrodidae), were conducted during 2014-15 in screen house of Department of Entomology College of Agriculture, CCS Haryana Agricultural University, Hisar on citrus mandarin (var. Kinnow). Results on biological studies of $D$. citri revealed that female on an average laid $151 \pm 42.99$ eggs with an incubation period of $13.3 \pm 1.89$ days. The mean duration of first, second and third instar nymphs were $13.1 \pm 1.77,11.1 \pm 2.05$ and $15.4 \pm 2.41$ days, respectively. The pupal duration was $108.3 \pm 4.33$ days. Adult Male lived for $16.5 \pm 1.96$ days whereas adult female lived for $18.6 \pm 2.06$ days. The male whitefly completed its life cycle in $178.8 \pm 6.73$ days whereas the corresponding period for female whitefly was $180 \pm 7.02$ days. This study established that biology of the insect is rather a stable trait because no significant variation was observed when compared with decade old reports despite the fact that agro-ecology including weather phenomenon have undergone significant change in the last decade.
\end{abstract}

Keyword: Biology, Citrus, Dialeurodes citri, Kinnow, Weather conditions

\section{INTRODUCTION}

Citrus (Rutaceae: Geraniales) fruits have the place of prides among the fruit crops grown in India and rank third after mango and banana. Among the various citrus fruits, Lime, lemons, sweet oranges and mandarin cover major area and are mainly grown in the state of Maharashtra, Andhra Pradesh, Karnataka, Odissa, Madhya Pradesh, Punjab and Haryana. In India, the citrus fruits occupy an area of 1042 (000'ha) with production of 10090 (000'MT) . The corresponding figures for the state of Haryana are 18.8 (000'ha) and 225.1 (000’MT), respectively (Anonymous, 2013). In Haryana, the major citrus growing districts are Sirsa, Hisar, Bhiwani, Gurgaon and Fatehabad.

Citrus plants are infested by large number of insectspests causing heavy yield penalty and even the qualitative loss becomes apparent. Among the sucking pests, whitefly, Dialeurodes citri Ashmead (Hemiptera: Aleyrodidae) is serious one which causes damage to citrus fruits by removing significant amount of phloem sap resulting in reduced plant vigour and yield. Secretion of honeydew by this pest results in development of sooty mould growth on fruits causing further loss to the growers in terms of quality deterioration and consequent low market price (Dhiman and Batra, 1998; Dhiman et al., 2000). For the successful cultivation of citrus fruit plants effective management of this insect is essential prerequisite. A thorough knowledge about the biology of an insect-pest is essential for evolving sound management package. Having regard to the fact that research work on this aspect is scanty and the review of literature revealed that practically no work on the biology of this insect was done in the last decade. The biology of $D$. citri has not yet been studied under agro-climatic conditions of Haryana. The biology of $D$. citri has not yet been studied under agro-climatic conditions of Haryana. It was in this endeavour that the present study was carried out to study of the biology of this pest under the agro-climatic conditions of Haryana and to know whether change in agro-ecology and climatic changes occurring in last decade has exerted any significant change in the biology of this insect pest.

\section{MATERIALS AND METHODS}

This study on the biological parameters of citrus whitefly, Dialeurodes citri (Ashmead) was conducted during August 2014-March 2015 in screen house of Dept. of Entomology, College of Agriculture, CCS Haryana Agricultural University, Hisar, Haryana. For the purpose of this study one year old plant of Citrus reticulate (Mandarin) var. Kinnow were transplanted in pots in the screen house. The males and females of $D$. citri were identified on the basis of their distinguishing morphological characters. The females are bigger in size and have blunt abdominal tip, while the males are smaller in size and have pointed abdominal tip. Whitefly adults were collected from citrus plants from the citrus orchards in the farm area of CCSHAU, Hisar, using aspirator and were released on the caged (size: $10 \mathrm{~cm}$ length and $3.5 \mathrm{~cm}$ diameter) leaves in the screen 
house. One pair of newly emerged adults was released per cage and 20 such plastic vial cages were tied to the freshly developed twig (bearing 2-3 leaves) of 10 potted plants@2 cages per plant.

The duration of developmental stages i.e. nymphal instars, pupal period were recorded by observing 100 individuals for each stage. For recording the adult longevity of $D$. citri, fully matured red eye pupae were observed till the emergence of adults started. The duration of adults in each cage was recorded daily and longevity of each sex was calculated. For recording preoviposition, oviposition, post-oviposition period and adult longevity, the newly emerged pairs of $D$. citri were collected and confined in new plastic vial cages in 20 replications. Each cage was observed daily during oviposition period for recording the fecundity of female. The numbers of eggs laid by female on the leaves were examined. For this, the leaf enclosed in each cage was taken out gently and observed by using 10X lens and each day the eggs laid were marked for determining daily fecundity. Such leaves were again enclosed in the cages for further egg laying by the females. The time period between laying of eggs and appearance of the crawlers was taken as incubation period.

The observation on per cent hatchability, pupation and adult emergence was recorded by observing one hundred of eggs, nymph and pupa, respectively. The length and width of different stages were measured with the help of ocular micrometer by observing 10 individuals of each stage viz. egg, first instar nymph, second instar nymph, third instar nymph, pupa and adult (male and female) under the stereoscopic zoom binocular microscope. Observations on pre-oviposition period (days), oviposition period (days), postoviposition period (days), adult longevity (day), fecundity, incubation period (days), hatchability (\%), number and duration of nymphal instars, per cent pupation (\%), pupal period (days), adult emergence (\%) and total life cycle (days) were recorded during biological studies. The data so collected was statistically analyzed by calculating mean value and standard deviation.

\section{RESULTS AND DISCUSSION}

Observations on different biological parameters recorded for various development stages of $D$. citri i.e. egg, nymph, pupa and adults and their duration on citrus (var. Kinnow) are presented in Table 1 and images of different stages are given in plate 1 . The measurements for different stages of the pest are provided in table 3 .

Egg: The eggs were laid singly on the lower surface of leaf and each egg was firmly attached to the leaf tissue by pedicel. The freshly laid eggs were pale yellow, translucent, sub-elliptical and smooth. The mature eggs became dirty white in colour and opaque. The mean length and width of freshly laid eggs without pedicel was observed to be $0.226 \pm 0.02$ and $0.078 \pm 0.01 \mathrm{~mm}$, respectively. The mean incubation period was found to be $13.3 \pm 1.89$ days (10-16 days). During egg stage, the temperature and relative humidity was $17.4-24.5^{\circ} \mathrm{C}$ and 60-74\%, respectively. Makar (1980) observed that the eggs laid by female $D$. citri, hatched in an average period of 18.5 days. Fasulo and Weems (2014) also reviewed and compiled report of different workers and reported that the eggs of $D$. citri hatched in 8-24 days, depending upon the season. Thus, seasonal variations affect the incubation period.

\section{Nymph}

First instar: The first instar nymphs (i.e. the crawlers) were observed as flattened, oval and pale yellow in colour with well developed antennae and legs. These nymphs crawled over the lower surface of leaf for few hours to establish feeding site. The mean length and the width of the freshly emerged nymphs were observed to be $0.301 \pm 0.02$ and $0.196 \pm 0.01 \mathrm{~mm}$, respectively. The first instar nymphal stage lasted for 10-16 days with a mean duration of $13.1 \pm 1.77$ days. During this stage, the temperature and relative humidity was 21.8-27.2 ${ }^{\circ} \mathrm{C}$ and 52-81\%, respectively. Makar (1980) observed that the young larva crawled for 3-4 hours before embarking to feeding. Husain and Khan (1945) observed similar results that the first instar nymph of citrus whitefly measured 0.28 to $0.31 \mathrm{~mm}$ length, 0.15 to $0.33 \mathrm{~mm}$ breadth. The duration of first instar nymph of $D$. citri was lasted for 10-16 days during September. Gupta and Joshi (1973) reported similar findings that the first instar nymphal stage lasted for 14-25 day in July to September. Bellows and Meisenbacher (2007) observed that the variation occurred in nymphal instars duration due to the variation in weather parameters (temperature and relative humidity).

Second instar: The first instar nymphs moulted and transformed themselves into second instar nymphs. The second instar nymphs were observed to be flattened, oval and dull white and transparent, became yellowish after some time of feeding. The second instar nymphs showed reduced antennae and legs. The mean length and the width of the freshly formed second instar nymphs were observed to be $0.457 \pm 0.05$ and $0.349 \pm 0.07 \mathrm{~mm}$, respectively. The second instar nymphal stage lasted for 8-15 days with a mean duration of $11.1 \pm 2.05$ days. During second nymphal instar, the temperature and relative humidity was $20.8-25.9{ }^{\circ} \mathrm{C}$ and 56-77 \%, respectively. Fasulo and Weems (2014) reviewed and compiled report of different workers and reported similar results that the nymphs lose their normal legs and antennae after first moult. The length and width of the freshly formed second instar nymph varied from $0.390-0.512 \mathrm{~mm}$ and $0.260-0.451 \mathrm{~mm}$, respectively. Hume (1957) reported that the length of the second instar nymph was $0.48 \mathrm{~mm}$ and width was $0.31 \mathrm{~mm}$. The duration of second instar nymph lasted for 8-15 days with a mean duration of $11.1 \pm 2.05$ days. Gupta and Joshi (1973) showed similar results that second instar duration varied from 10-26 days. 


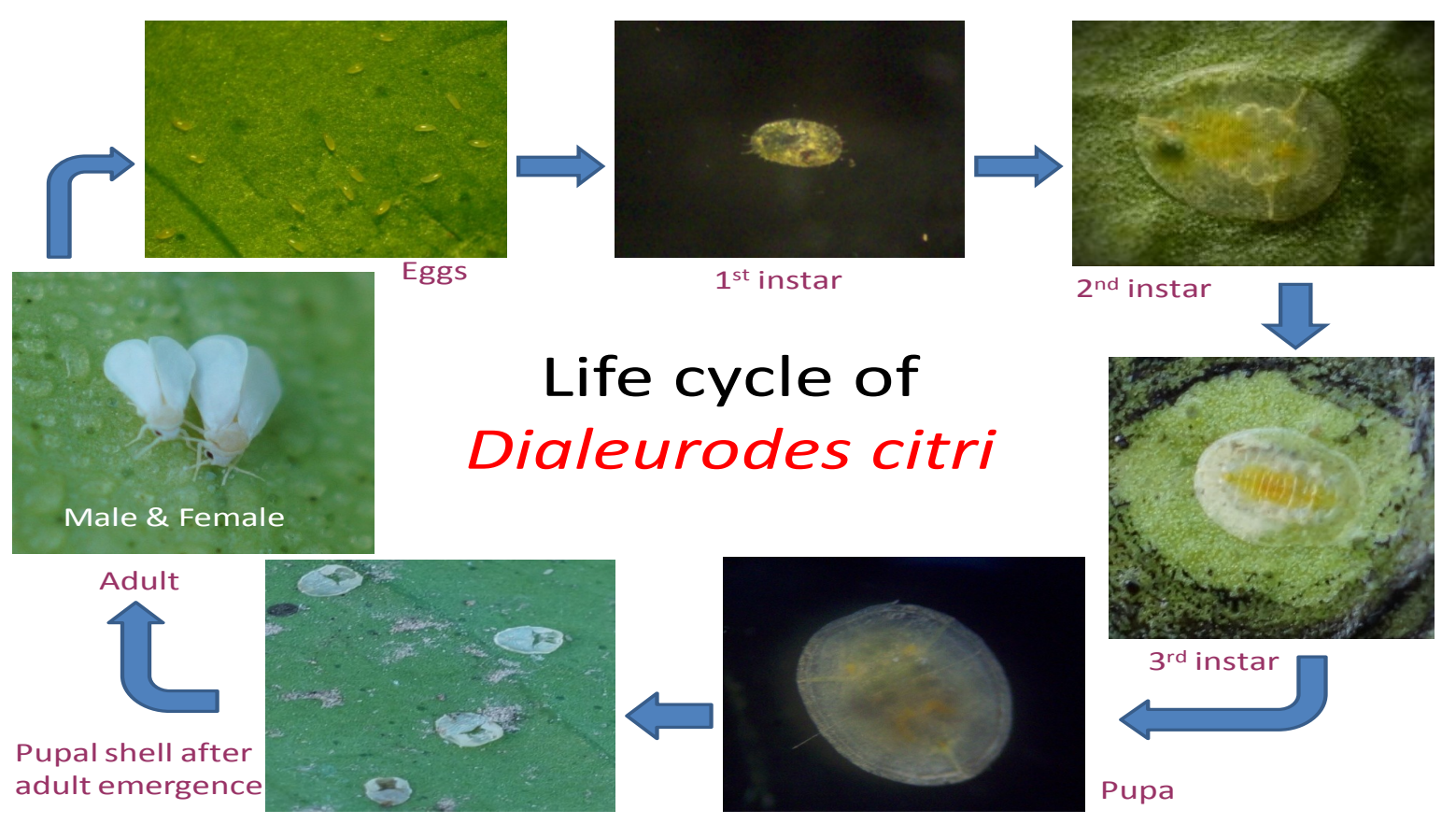

Plate 1. Different life stages of D. citri on citrus.

Table 1. Duration of different developmental stages of D. citri on citrus during September 2014-March 2015.

\begin{tabular}{lccc}
\hline \multicolumn{1}{c}{$\begin{array}{c}\text { Parameter } \\
\text { (Insect stage/Duration) }\end{array}$} & $\begin{array}{c}\text { Number } \\
\text { Observed }\end{array}$ & \multicolumn{2}{c}{ Mean duration (days) } \\
\cline { 3 - 4 } Incubation period (eggs) & 100 & $13.3 \pm 1.89$ & Range \\
\hline Nymph & 100 & $10-16$ \\
\hline 1st instar nymphal period & 100 & $11.1 \pm 2.05$ & $10-16$ \\
2nd instar nymphal period & 100 & $15.4 \pm 2.41$ & $8-15$ \\
3rd instar nymphal period & 100 & $108.3 \pm 4.33$ & $11-18$ \\
Pupa & & & $98-115$ \\
\hline Adult & 20 & $3.8 \pm 0.83$ & $2-5$ \\
\hline Pre oviposition period & 20 & $12.9 \pm 2.61$ & $0-17$ \\
Oviposition period & 20 & $1.9 \pm 1.02$ & $14-22$ \\
Post oviposition & & & $13-19$ \\
\hline Adult longevity & 20 & $18.6 \pm 2.06$ & $167-191$ \\
\hline Female & 20 & $16.5 \pm 1.96$ & $165-187$ \\
Male & & $180 \pm 7.02$ & $109-250$ eggs \\
\hline Total life cycle & & $178.8 \pm 6.73$ & \\
\hline Female & 20 & $151 \pm 42.99$ eggs & \\
Male & &
\end{tabular}

Bellows and Meisenbacher (2007) also reported that the development time taken by $D$. citri second instar nymph varied from 6.7-10.5 days.

Third instar: The second instar nymphs moulted and transformed themselves into third instar nymphs. The freshly moulted third instar nymphs were also observed to be oval, flattened, white translucent, shiny with pulpy appearance. The mean length and width of the freshly emerged third instar nymphs were observed to be $0.740 \pm 0.07$ and $0.55 \pm 0.06 \mathrm{~mm}$, respectively. The third instar nymphal stage lasted for 11-18 days with a mean duration of $15.4 \pm 2.41$ days. During third nymphal instar, the temperature and relative humidity was $16.7-25.2{ }^{\circ} \mathrm{C}$
Table 2. Hatchability, pupation and adult emergence of $D$. citri.

\begin{tabular}{lcc}
\hline Parameter & $\begin{array}{c}\text { Number } \\
\text { observed }\end{array}$ & $\begin{array}{c}\text { Percent- } \\
\text { age }\end{array}$ \\
\hline Hatching (\%) & 100 eggs & 84 \\
Pupation (\%) & 100 nymphs & 87 \\
Adult Emergence (\%) & 100 pupa & 67 \\
\hline
\end{tabular}

and 49-66 \%, respectively. Gupta and Joshi (1973) described that the body measures $0.61-0.67 \mathrm{~mm}$ in length and $0.46-0.57 \mathrm{~mm}$ in width. Hume (1957) also described the size of the third instar which was 0.70 to $0.75 \mathrm{~mm}$ in length and 0.50 to $0.58 \mathrm{~mm}$ in width.The duration of third instar nymph lasted for 11-18 days with a mean dura- 
Tekchand Saini et al. / J. Appl. \& Nat. Sci. 8 (4): 1735-1739 (2016)

Table 3. Measurements of different stages of $D$. citri.

\begin{tabular}{|c|c|c|c|c|}
\hline \multirow{2}{*}{ Insect stage* } & \multicolumn{2}{|c|}{ Length (mm) } & \multicolumn{2}{|c|}{ Width (mm) } \\
\hline & Mean \pm SD & Range & Mean \pm SD & Range \\
\hline Egg & $0.226 \pm 0.02$ & $0.200-0.250$ & $0.078 \pm 0.01$ & $0.07-0.092$ \\
\hline 1st nymphal instar & $0.301 \pm 0.02$ & $0.285-0.331$ & $0.196 \pm 0.01$ & $0.188-0.205$ \\
\hline 2nd nymphal instar & $0.457 \pm 0.05$ & $0.39-0.512$ & $0.349 \pm 0.07$ & $0.26-0.451$ \\
\hline 3rd nymphal instar & $0.74 \pm 0.07$ & $0.66-0.830$ & $0.55 \pm 0.06$ & $0.49-0.630$ \\
\hline $4^{\text {th }}$ instar (Pupa) & $1.404 \pm 0.03$ & $1.36-1.440$ & $1.101 \pm 0.04$ & $1.048-1.153$ \\
\hline Adult: & & & & \\
\hline Male & $0.965 \pm 0.09$ & $0.845-1.076$ & - & - \\
\hline Female & $1.153 \pm 0.07$ & $1.076-1.276$ & - & - \\
\hline
\end{tabular}

* 10 observations for each stage

tion of $15.4 \pm 2.41$ days. Similar results were reported by Gupta and Joshi (1973) who reported that the third instar nymph duration varied from 13-21 days. Bellows and Meisenbacher (2007) also reported that the development time taken by $D$. citri third instar nymph varied from 10.4-13.3 days. He further studied and concluded that the variation occurred in nymphal instars duration due to the variation in weather parameters (temperature and relative humidity).

Fourth instar (Pupa): Newly formed pupa were white, opaque, flattened, oval in shape and larger than other nymphal instars. After some days colour of pupa became yellowish and eye spots were distinctly visible. The mean length and width of the newly formed pupae was observed to be $1.404 \pm 0.03$ and $1.101 \pm 0.04 \mathrm{~mm}$, respectively. The pupal stage lasted for 98-115 days with a mean duration of $108.3 \pm 4.33$ days. The pupal duration was quite long due to the reason that prevailing lower temperature coupled with shorter days induced the fourth instar nymphs to enter in diapause. The temperature and relative humidity during pupal stage was $7.5-22.0{ }^{\circ} \mathrm{C}$ and 56-99 \%, respectively. Fasulo and Weems (2014) reviewed and compiled report of different workers and reported similar findings that the pupae were similar to nymphs in colour and shape but are thickened and are somewhat opaque and eye spots of the developing adult may show through the pupal skin. The length and width of the newly formed pupae varied from $1.360-1.440 \mathrm{~mm}$ and 1.048 - $1.153 \mathrm{~mm}$, respectively. Argov et al. (1999) stated that citrus whitefly entered in diapause with shortening of days and decrease in temperature, and diapause occurring in the fourth instar was facultative, induced by shortening of day.

Adult and total life cycle: The fully developed adult emerged through an inverted ' $\mathrm{T}$ ' shaped slit in the dorsal surface of the pupal case. The adult female had prominent dark brown coloured compound eyes with smoky white wings and blunt ovipositor while male was comparatively smaller in size than female and had a narrow (pointed) abdomen. The mean length of the adult female and male was observed to be $1.153 \pm 0.07$ and $0.965 \pm 0.09 \mathrm{~mm}$, respectively. The longevity of adult female varied from $14-22$ days with a mean duration $18.6 \pm 2.06$ days while the longevity of adult male ranged from 13-19 days with mean duration of 16.5 \pm 1.96 days. The total life span of the female was $167-$ 191 days with mean duration of $180 \pm 7.02$ while the life span of male ranged from 165-187 days with mean duration of $178.8 \pm 6.73$ days. During adult stage (from emergence to till death), the temperature and relative humidity was $13.1-20.0{ }^{\circ} \mathrm{C}$ and $53-97 \%$, respectively. Similarly, Gupta and Joshi (1973) reported that the male of whitefly had body length of $1.16 \mathrm{~mm}$, was smaller than female which had body length 1.38 $\mathrm{mm}$. Similar results were reported by Fasulo and Weems (2014) also reviewed and compiled report of different workers and reported that the adult of whitefly was tiny, mealy-white insect with four mealy-white wings, covered with a white powdery wax. Female of D. citri had a blunt ovipositor while male was comparatively smaller in size than female and had a narrow (pointed) abdomen. Variation in total life cycle as described in present investigations and by different workers may be due to variation in weather parameters.

Fecundity: The number of eggs laid by female of $D$. citri varied from $109-250$ eggs during its oviposition period. The mean fecundity per female was $151 \pm 42.99$ eggs. The fecundity of $D$. citri female reported by Pruthi and Mani (1945) as 150 and by Gupta and Joshi (1973) as 69-189 corroborates the findings of this study.

Pre-oviposition, oviposition and post oviposition period: The pre-oviposition, oviposition and postoviposition period of adult female was 2.0 -5.0, 9.0 17.0 and $0.0-3.0$ days, respectively with mean duration $3.8 \pm 0.83,12.9 \pm 2.61$ and $1.9 \pm 1.02$ days, respectively. Targe and Deporters (1953) mentioned the pre-oviposition, oviposition and post oviposition period of female as 2-3, 6-11 and 0-2 days, respectively. Bellows and Meisenbacher (2007) reported the oviposition period of citrus whitefly female as 4-10 days. Some degree of variation in this study may be attributed to different ambient conditions during these studies.

Hatchability, pupation and adult emergence: The per cent hatchability, pupation and adult emergence of citrus whitefly was 84,87 and 67 , respectively (Table 2). During hatching of eggs the temperature and relative humidity was $17.4-24.5^{\circ} \mathrm{C}$ and $60-74 \%$, respectively. No information with respect to the other parameters is available in the literature. 


\section{Conclusion}

The information on the biology of any insect pest is a condition precedent to work out it control measures. Having regards to the fact that research work on this aspect is scanty and the review of literature revealed that practically no work on the biology of this insect was done in the last decade. This study established that biology of the insect is rather a stable trait because no significant variation was observed when compared with previous reports despite the fact that agro-ecology including weather phenomenon have undergone significant change in the last decade.

\section{REFERENCES}

Anonymous (2013). Statistical Abstract of Haryana 2 011-2012. Published by Department of Economic and Statistical Analysis, Haryana, pp. 130-258

Argov, Y., Rossler, Y., Voet, H. and Rosen, D.(1999). The biology and phenology of the citrus whitefly, Dialeurodes citri, on citrus in the Coastal Plain of Israel. Entomologia Experimentalis et Applicata, $93: 21$ $-27$

Bellows, T. S., Jr. Meisenbacher, C. (2007). Field population biology of citrus whitefly, Dialeurodes citri (Ashmead) (Heteroptera: Aleyrodidae), on oranges in California. Population Ecology, 49 (2): 127-134

Dhiman, J. S. and Batra, R. C. (1998). Eco-friendly approaches foe management of disease and pests in fruit crops. International Conference on Pest and Pesticide management for Sustainable Agriculture held at C.S.A.U.A. \& T., Kanpur, India (11-13 December, 1999) pp. 35-37

Dhiman, J.S. and Batra, R.C. and Sharma, D.R. (2000). Synchronous attack of insect pests and diseases in kinnow; Hitech citrus management, Proc. International Symposium on Citriculture at Nagpur, (Nov. 23-27) pp. 810-817

Fasulo, T.R. and Weems, H.V. (2014). Citrus whitefly, Dialeurodes citri Ashmead (Insecta: Hemiptera: Aleyrodidae). UF/IFAS Extension. EENY- 084 (IN241).

Gupta, B.P. and Joshi, N.K. (1973). Bionomics of citrus whitefly, Dialeurodes citri Ashmead at Chaubattia in U.P. hills. Progressive Horticulture, 5: 77-83

Hume, H.H. (1957). Citrus fruits, Revised ed., 28: 357-359

Husain, M.A. and Khan, M.A. (1945). The citrus Aleyrodidae (Homoptera) in Punjab and their control. Mem. Ent. Soc. India, 1: 1-41

Makar, P.V., Katole, V.U. and Choudhary, K.G. (1980). Biology of citrus whitefly Dialeurodes citri Ashmead and its reaction to the toxicity of few organophosphorous insecticides. Journal of Maharashtra Agricultural University, 5 (3): 256-257

Pruthi, H.S. and Mani, M.S. (1945). Our knowledge of the insects and mite pests of citrus in India and their control. Imperial Council of Agricultrue Science, Monograph, 16 (42): 137-149

Rahman, E.A. (1940). Insect pest of citrus in the Punjab. $P b$. Agri. Coll. Mag. Lyallpur (W. Pakistan), 7 (5-7): 1-98.

Targe, A. and Deporters, L. (1953). Dialeurodes citri Ash. dens les Alpes Maritmes Premiers resultants d' experimentation de traitments. Phytoma, 6 (44): 9-15 